\title{
El corral de aves domésticas en la cultura española
}

Desde los albores de la civilización el gallinero se ha constituido en un elemento inseparable de la cultura humana. La facilidad con que esta especie se ha adaptado y domesticado en los diversos medios geográficos, la sencillez de los cuidados requeridos y sus grandes rendimientos en carne y huevos son en el plano material sus características más apreciadas. A éstas, durante milenios, el hombre ha ido sumando otras puramente culturales cargando a gallos y gallinas de simbolismos y significaciones. Desde la superstición y la magia, hasta innumerables expresiones verbales o juegos infantiles, gallos y gallinas impregnan nuestra cultura.

Aunque ya egipcios y persas tenían explotaciones de gallinas a gran escala, estando documentada con los primeros la existencia de hornos para incubar artificialmente los huevos, en el occidente europeo, donde la gallinocultura fue difundida por griegos y romanos, hasta finales del siglo XVIII, no se comenzaron a desarrollar las explotaciones industriales. En España las granjas avícolas tuvieron un gran impulso a partir de 19551962 , suponiendo en la actualidad el 70 por 100 de la producción nacional, frente al 30 por 100 procedente de aves rurales o camperas ${ }^{1}$. Cataluña es la zona más modernizada e industrializada en contraposición a Galicia que aunque arroja el índice más alto en la producción, ésta se asocia al tradicional corral de aves domésticas, vinculado a las unidades familiares rurales. Este último tipo de explotación es característico de una economía de autoconsumo en la que el campesino trata de abastecerse del mayor número posible de los alimentos que requerirá durante el año. Si la ganadería mayor o la tradicional agricultura de secano sufren un proceso de decadencia, amenazadas por la falta de competitividad de las pequeñas explotaciones poco modernizadas y mecanizadas, la pequeña huerta y el corral muestran mucha mayor resistencia a su desaparición, precisamente por constituir la base alimenticia de la población rural. Es de este corral de aves domésticas con su enorme incidencia cultural y antropológica, del que trataremos de dar algunas notas en este breve estudio.

1 Ramón Tamames, Introducción a la economía española (Madrid: Alianza Editorial, 1976), pp. $160-161$. 
Los corrales tradicionales, donde además del gallinero se suelen criar varios conejos y algún pato o pavo, se vinculan a la unidad familiar y hasta tal punto son comunes que, en los territorios sometidos a la dominación señorial (mayorazgos, ducados, condados, etc.), existía un impuesto especial, "El Don" $\mathrm{O}$ "El Regalo" consistente en que cada vecino diera un determinado número de gallinas una vez al año, normalmente por Navidad. Aún hoy, en Villanueva del Cauche (Málaga), los habitantes de este marquesado se ven sometidos a esta atávica tradición. También mantiene su vigencia la costumbre de que los colonos de cortijos y otras explotaciones agropecuarias abastezcan de huevos y pollos procedentes de sus corrales, al propietario o amo, o que se estipule la entrega de un determinado número de aves al año.

Dentro de la división de funciones, masculinas y femeninas, en el mundo rural español, el gallinero se asocia a la mujer, que es quien, en general, se ocupa de todos sus cuidados (alimentación de las aves, limpieza y aprovechamiento de productos), con un marcado carácter de autoabastecimiento. Así en la cultura tradicional española una mujer debe saber tanto matar y desplumar una gallina, como desollar un conejo, formando parte de las labores propias de su sexo. En muchas localidades el corral forma o formaba parte del ajuar que la novia debía aportar a la nueva familia y el regalo de un gallo vivo o una gallina estaba muy extendido en las bodas. Esta asociación por otra parte, no suele ser excluyente y también ancianos y criados pueden encargarse del degüello y desplume de las aves, aunque rara vez se dediquen a estas labores los varones en plena capacidad productiva.

Con el propósito de facilitar sus cuidados diarios, pero sobre todo para proteger a las aves de las alimañas, los corrales domésticos se ubican dentro del núcleo urbano, bien ocupando el subsuelo o sótano de la propia vivienda familiar, bien dentro de la cuadra en estancias aisladas. En contraposición con las normas de higiene y salubridad más elementales, suelen ser lugares pequeños, húmedos y oscuros con poca luz natural y sin más ventilación que el pequeño orificio por el que los animales acceden al exterior, el cual se bloquea durante las noches. Ocasionalmente pueden aparecer gallineros elevados sobre el nivel del suelo, como los documentados en la Sierra Norte de Madrid accediendo a ellos las gallinas por medio de rudimentarias escalerillas.

Cuando se poseen diversas especies de animales de corral (gallinas, pavos, conejos, etc.) éstos ocupan estancias y comederos independientes en el interior, aunque durante el día las aves puedan compartir el espacio exterior. Igualmente se deben aislar a las crías y los animales heridos o enfermos para preservarlos del atque de sus compañeros.

El principal cuidado con las gallinas y otros animales de corral en la actualidad es su alimentación diaria a base de granos de maíz y todo tipo 
de desperdicios alimenticios o residuos hortofrutícolas (verduras, frutas, cáscaras de patatas cocidas...) que pueden sustituirse por piensos. Para aportar calcio es conveniente dar a las gallinas huesos molidos y cáscaras de huevo. Tanto estas aves como los pavos son omnivoros y deben ingerir otros alimentos naturales como gusanos, ortigas u otras hierbas. Todavía hoy es normal en las áreas rurales que, durante el día queden en completa libertad para procurarse estos últimos alimentos, volviendo por sí mismas a los corrales, al caer la tarde.

En la actualidad incluso en los corrales rurales familiares, se adquieren los pollitos de exterior evitándose los cuidados de reproducción. Tradicionalmente se vigilaba cuando las gallinas estaban cluecas, es decir con una especie de celo que las impulsa a incubar los huevos después de haber sido fecundadas. En este momento, caracterizado por un cacareo especial denominado cloqueo, se le dan de doce a veinte huevos para que los empolle, colocándolos en un cajón, en lugar resguardado, húmedo y oscuro. La incubación se prologan durante veinte, veintiún días ${ }^{2}$, durante los cuales el propietario debe cuidar el proceso, apartando los huevos no fecundados y aquellos en los que el feto muere y obligando a la gallina a separarse, al menos dos veces al día del nido, para recuperar fuerzas, a lo cual se contribuye con su cebado o sobrealimentación. Las pavas en cautividad no incuban sus huevos y éstos que se destinan siempre a la reproducción, se les dan a una gallina clueca.

La obtención de huevos es el principal fin del gallinero. En las granjas avícolas se distinguen entre gallinas ponedoras y no ponedoras, dedicando las segundas al aprovechamiento cárnico y obteniendo de las primeras una media de doscientos cincuenta a trescientos huevos anuales, gracias a la constante calefacción, la sobrealimentación e incluso el empleo de medios más sofisticados; como, a través del encendido y apagado de luces, simular días más cortos. Las gallinas camperas ponen una media de unos cien anuales concentrándose las puestas en los meses estivales. El consumo de huevos es muy elevado en la alimentación rural, siendo normal la ingestión de uno o dos diarios durante el almuerzo o la cena, además de emplearse en la elaboración de rosquillas y dulces tradicionales. Esto obliga al propietario rural a la posesión de un alto número de aves para asegurar el abastecimiento en todas las épocas del año. En verano se crean excedentes que, en pequeña medida, se tratan de comercializar en establecimientos locales o también, se regalan a familiares, veraneantes y personalidades.

Los pollos machos, exceptuando al que se selecciona como semental, se dedican a la alimentación constituyéndose en un apreciado plato que, en otros tiempos, se destinaba a ocasiones más o menos festivas (estaba

\footnotetext{
2 Fruela Prerfda, Avicultura y cunicultura (Madrid: Publicaciones Españolas, 1954).
} 
muy difundida la costumbre de consumirlos los domingos). Hoy por la bajada comparativa de su precio y la generalizada elevación del nivel de vida, su consumo está mucho más extendido habiendo perdido su carácter de comida especial en las zonas urbanas, aunque en las fiestas y otras conmemoraciones rurales sigue ocupando un papel destacado en los menús. Igualmente es proverbial la bondad del caldo de gallina, especialmente indicado para ancianos, parturientas y convalecientes de todo tipo.

Los pavos, aunque en los últimos tiempos se ha extendido mucho su cría a nivel industrial, son raros en los corrales rurales. Usualmente sólo se engordaba uno al año para sacrificarlo en Navidad (la costumbre es de origen anglosajón). Menos extendida está en España la práctica, muy común en Francia, de criar y cebar patos tanto para su consumo directo como para la obtención de foie-gras que, cuando procede del hígado de este animal, se considera un producto de lujo. Por otra parte, la carne de conejo tanto de corral como de caza ha supuesto una importante fuente para la obtención de proteínas de origen animal, sobre todo en épocas de carestía o crisis agropecuarias.

Además de los huevos y carne, de las aves de corral son aprovechadas las plumas tanto para usos domésticos como, sobre todo, para su comercialización. Las de los pavos, muy apreciadas, se les pueden arrancar en vivo dos veces al año, además de al morir.

Por último, las palomas en algunos casos pueden considerarse como animales de corral, aunque ocupan siempre estancias independientes, bien en la parte alta de las viviendas, bien en palomares exentos que por su riqueza y variedad merecen un estudio arquitectónico independiente. Con ellas los cuidados son mínimos y una vez instaladas varias parejas y avezadas (acostumbradas a volver al palomar), sólo hay que ocuparse de darles agua y grano, aunque ellas también son capaces de procurarse alimentos por sí mismas. Sí se debe tratar que críen en los aquerenciadores, pequeñas estancias aisladas que empalman con el palomar. Esta pacífica ave que en libertad se ha adaptado a los ámbitos urbanos formando parte del paisaje de numerosas plazas e iglesias y llegando a comer de la mano de turistas y transeúntes, tiene aprovechamientos muy variados. Su consumo es restringido, pero también se crían y venden de forma masiva para la práctica de tiro de pichón. Existen infinidad de razas y variedades, siendo la más extendida en los palomares españoles la buchona. Otras como las mensajeras, de origen belga, por su extraordinario sentido de la orientación, han supuesto un elemento vital para las comunicaciones civiles y militares en épocas pasadas. Aún en la actualidad, en España hay que notificar a la Guardia Civil la posesión de palomas mensajeras y el dueño debe afiliarse a la Sociedad Colombófila. El uso de quinterones (también denominados palomos 
buchones-ladrones-ideales) está prohibido, ya que por su gran vistosidad son capaces de atraer a las palomas de otros palomares. Para la caza se han empleado y emplean como reclamo tanto de palomas torcaces o silvestres como de gavilanes $u$ otras aves de presa ${ }^{3}$.

La enorme incidencia que en la vida material tienen los animales de corral, especialmente gallos y gallinas, ha quedado reflejada en múltiples aspectos de toda la cultura humana, desde el vocabulario a las fiestas, pasando por las supersticiones y prácticas curativas o el más puro simbolismo. Están muy extendidos refranes ${ }^{4}$ y comparaciones antropomorfas basadas en la observación de su personalidad, características físicas o comportamiento, tales como "más cotorra que una gallina", "piel de gallina", etc. También están presentes en los cuentos, las fábulas, las canciones de corro e innumerables juegos infantiles, siendo un ejemplo ya clásico el de "la gallinita ciega" o adivinanzas como:

\author{
Alto altanero \\ Gran caballero \\ Gorra de grana \\ Capa dorada \\ Y espuela de acero
}

(El gallo)

En los testamentos como género literario popular, contamos con varias versiones o variantes del testamento del gallo ${ }^{5}$. Es, como el de otros animales, de carácter satírico, y se solía recitar antes de su sacrificio ritual en las corridas de gallos y otras ocasiones. En él, además de la repartición de fabulosas propiedades, se legan las diversas partes del cuerpo de acuerdo con las necesidades y características del receptor ${ }^{6}$ :

$$
\begin{aligned}
& \text { «...que las plumas de mis alas } \\
& \text { les mando a los escribientes... } \\
& \text {...mando mi pico a las mujeres } \\
& \text { que fueren largas de lengua... }
\end{aligned}
$$

\footnotetext{
s Mario J. Conde, Palomas y palomares (patos, pavos, gansos, ocas, pintadas) (Madrid: Ediciones Ibéricas. Pequeña Enciclopedia Práctica, núm. 96, s.f.).

4 Fernando De Castro Pires de Lima, Galinhas e ovos na advinha popular, RDTP, VII (1951), pp. 653-684; Vicente GARCIA DF Difgo, *Voces a los animales, RDTP, XVIII (1962), pp. 289-338; A. González Palencia, .Fórmulas populares para incubar. Horcajo de Santiago (Cuenca), RDTP, 1 (1945), pp. 346-347.

5 Joan Amades, .El testamento de animales en la tradición catalanan, RDTP, XVIII (1962), pp. 339-394; Antonio Fragias Fraguns, -Máscaras y sermones en Cotobad-, RDTP, II (1946), pp. 441-442; Pilar Garcia de Diego, .El testamento en la tradición popular. Testamentos de víctimas", RDTP, IX (1953), pp. 601-666.
}

- Pilar Garcia de Diego, op. cit., pp. 623-624. 


$$
\begin{aligned}
& \text {...que se coma mi cabeza } \\
& \text { quien menos seso tuviere... } \\
& \text {...mis tripas mando a violeros } \\
& \text { para cuerdas de discantes.... }
\end{aligned}
$$

El gallo como único macho en el corral de gallinas, se ha convertido en un símbolo de fertilidad masculina y como tal ha sido víctima propiciatoria en sacrificios rituales ya desde épocas clásicas ${ }^{7}$. Las cruentas corridas de gallos, presentes en numerosas localidades españolas y vinculadas al carnaval y otras fiestas locales, consisten en la decapitación de un ejemplar vivo suspendido de una cuerda. Los participantes deben realizar el acto sólo con el tirón de las manos, subidos a un caballo al galope, o con un sable y los ojos vendados. También se ha documentado el sacrificio de gallos enterrados hasta el cuello y decapitados en este caso por una doncella, valiéndose de una espada. Algunos actos de elevada significación en la vida rural, como la siega, igualmente se acompañaban a veces del sacrificio ritual de este animal para asegurar la bondad y fertilidad de las próximas cosechas. En todos los casos, el gallo sacrificado es posteriormente cocinado y consumido por los participantes en fiestas subsiguientes.

Los gallos de pelea ${ }^{8}$ que requieren toda una cría y cuidados especiales, fueron famosos en Valencia y Andalucía y hoy mantienen su vigencia en las Islas Canarias, seguramente por influencia suramericana. Las principales cualidades de estos animales son su agresividad y valor, que les impulsan a luchar hasta la muerte. El gallo de pelea ha dado lugar a la expresión "gallito" referida a individuos de comportamiento altanero y agresivo. Otras manifestaciones culturales asociadas a los gallos entran dentro de la mitología popular ${ }^{9}$, como la creencia en que el gallo pone un sólo huevo en su vida, cuando ya es viejo, del cual nace un basilisco o una serpiente. Además su costumbre de lanzar quiquiriquíes al amanecer, le ha hecho constituirse en un símbolo del día, la luz, la resurrección y la vida, frente a la noche, las tinieblas y la muerte. Por esta misma razón, su representación encima de las veletas en la parte más alta de los tejados de las viviendas, se utilizaba como espantabrujas". También

Guadalupe GONZAIFZ HoNTORIA, "El animal como protagonista en los carnavales españoles.. Narria, núm. 31 (1983), pp. 3-9; M. Marcos df Sande y José De ia Fúfnte Caminals, -Corridas de gallos", RDTP, VIII (1952), pp. 154-1558.

* María Luisa Gonzalfz Pena, «Las peleas de gallos en la isla de Gran Canarian, Narria, núm. 18 (1980), pp. 18-19; Enrique J'sto, "Las peleas de gallos;, RDTP. XXV (1969), pp. 317-323.

Vicente Risco, ‘La procesión de las ánimas y las premoniciones de muerte, RDTP, II (1946), pp. 380-429; idem, “Creencias gallegas. Tradiciones referentes a algunos animales", RDTP, III (1947), pp. 374-377; Ramón VIOL.ANT Y SimORRa, "Los animales de color negro en las supersticiones españolas;, RDTP, IX (1953), pp. 272-328. 


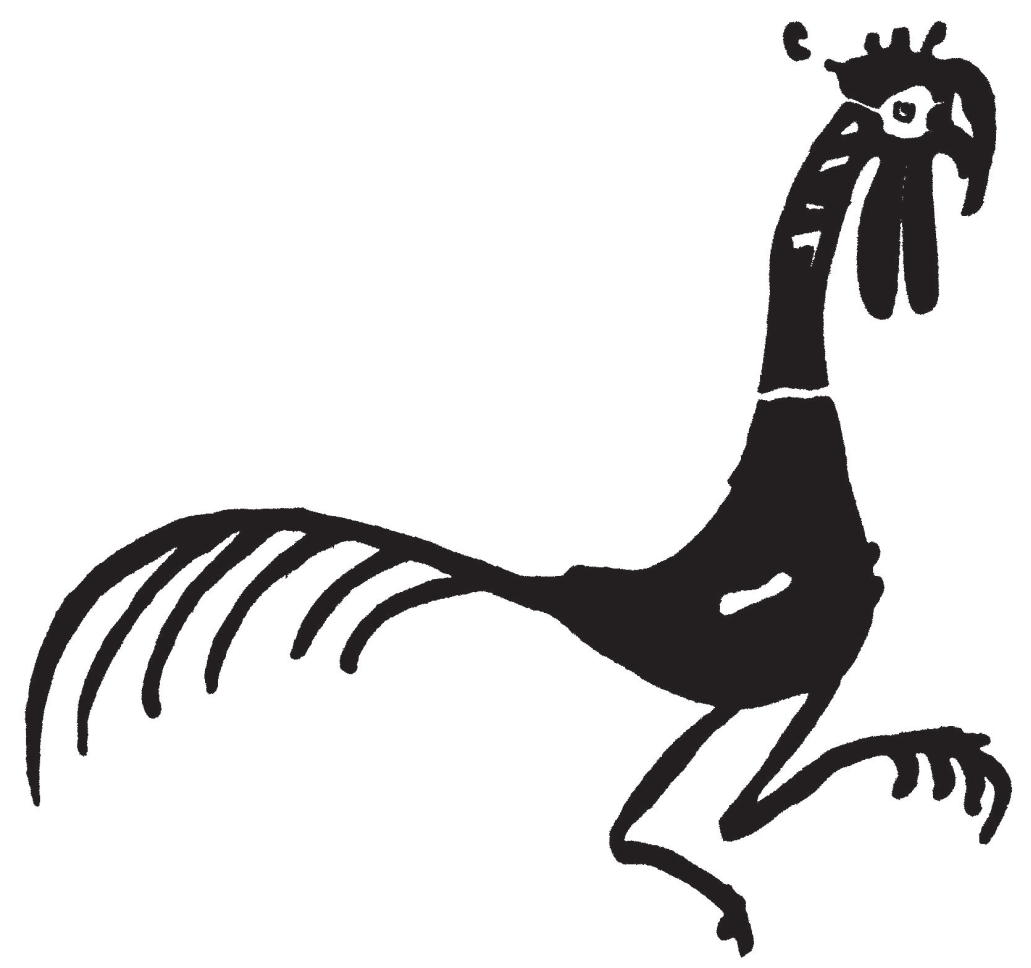

FiG. 1.-Gallo pintado en cerámica. Cultura ibérica. Fossal de Manises (Alicante). Según Trinidad Tortosa.

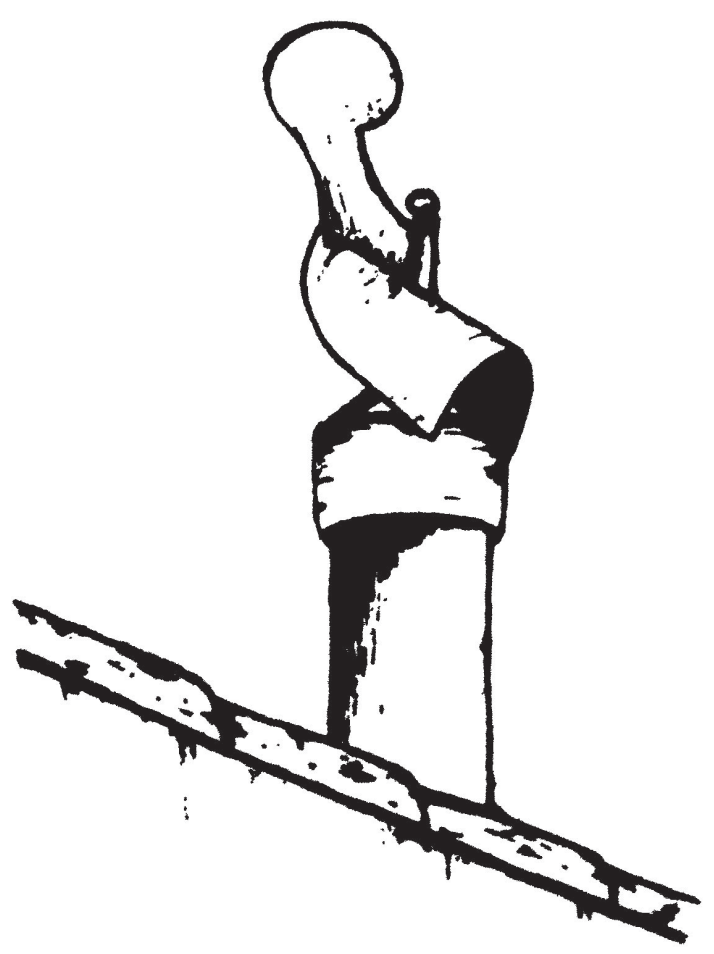

Fig. 2.-Chimenea de estufa rematada en veleta con figura de gallo. Gallocanta (Teruel). Según Carlos Laffon. 


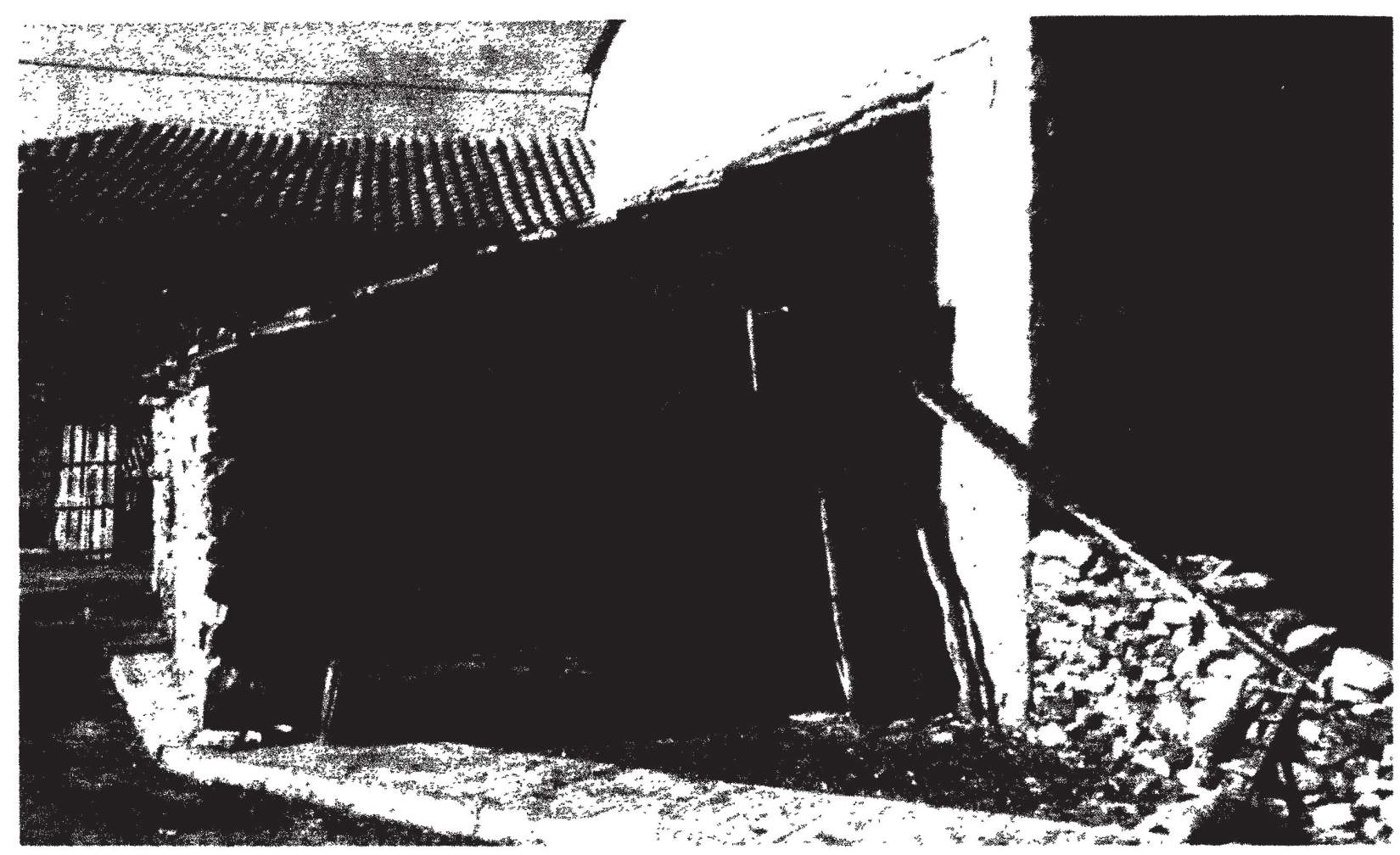

LAM. 1.a-Gallinero elevado. Gandullas (Madrid). Foto INTERARQ.

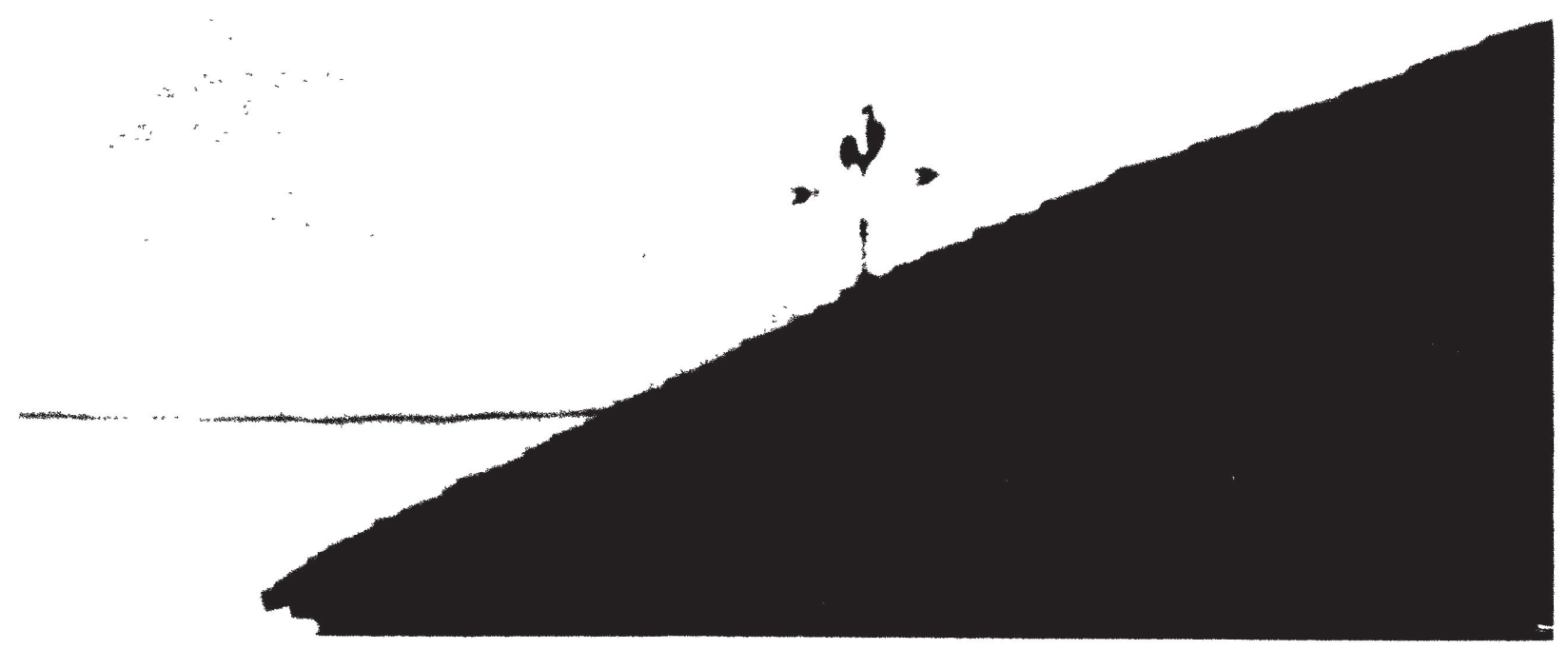

Lai. II.b.-Veleta rematada en figura de gallo. Berruecos (Teruel). 
la asociación de la forma de su cresta con el sol ha reforzado su sin' . ...) solar. Arte y artesanías populares en las más variadas materias rephimen una y otra vez su imagen.

En contraposición a las nobles virtudes y simbología del gallo, las gallinas se consideran cobardes, poco inteligentes, ruidosas y muy revoltosas. Está generalizada la comparación de ciertas reuniones de gran griterío y desorden con los gallineros dando nombre al anfiteatro superior de los teatros donde se localizan las entradas más baratas. Su capacidad de poner un huevo diario, aunque no suelan estar fecundados, ha generado injustas expresiones como "más puta que una gallina" referida a mujeres de conducta licenciosa. En la misma línea peyorativa existe una superstición, documentada tanto en diversos puntos de España como en Bretaña, Escocia y Gales, según la cual cuando una gallina cacarea como un gallo realiza una premonición de muerte sobre su propietario o sus familiares directos. Según esta creencia el augurio se puede contrarrestar matando inmediatamente a la nefasta ave. En ocasiones su significado cultural es algo más benigno: el celo con que incuban y cuidan a sus polluelos que mantienen calientes cubriéndolos bajo sus alas, ha hecho de la imagen de una gallina empollando o rodeada de sus crías, un símbolo de maternidad y dulzura y también ha creado expresiones como "estar o esconderse bajo el ala", referidas a personas que no se despegan de la familia o tienen un comportamiento temeroso e irresoluto.

Los contenidos simbólicos afectan también a los huevos de gallina que en épocas clásicas se representaban con cierta frecuencia en las tumbas, estando considerado como un símbolo funerario. Sin embargo, será el cristianismo el que más asiduamente lo utilice también asociado a la muerte pero como claro símbolo de resurrección. El huevo de pascua, pintado y decorado, formando plarte de panes y bollos característicos como el hornazo, o reproduciendo su forma en huevos de chocolate, es un alimento típico del Domingo de Resurrección, aunque la práctica de vaciar los huevos conservando intacta su cáscara para su posterior decoración, está muy extendida asimismo en civilizaciones orientales.

Las supersticiones y creencias sobre gallos y gallinas también afectan a sus colores ${ }^{10}$. Así en Galicia y Cataluña se considera que los gallos negros traen suerte y riquezas y las gallinas de este color son más fértiles. Además, el primer caldo que tomaba una parturienta debía proceder de una gallina negra (blanca en algunas otras localidades) para propiciar la rápida recuperación de la mujer. Tanto sus huevos como la propia gallina negra, su sangre, cresta y otras partes de cuerpo se emplean, según creencias populares, para alargar la vida y sanar diversas dolencias. En otras versiones del norte peninsular (Navarra, País Vasco y Asturias) las

R. Violayt Y Simorra. op. cit. 
gallinas negras no sólo ahuyentan la suerte y propician desgracias, sino que, además, son un medio del que se valen las brujas para sus sortilegios.

Otra ave doméstica cargada de significación cultural es la paloma. Por su estricta monogamia y los arrullos que acompañan el apareamiento, se considera un símbolo de pureza, amor, inocencia y fidelidad. También, y en contraposición al águila o al gavilán que representan el poderío, la majestad y la guerra, la paloma es un símbolo de paz universalmente aceptado. El origen de esta simbología debe remontarse a los relatos bíblicos cuando una paloma anunció a Noé el descenso de las aguas. También la representación del Espíritu Santo como paloma, forma en que se manifiesta a los hombres, ha contribuido a la beatificación de este animal.

\section{MATILDE FERNÁNDEZ MONTES \\ CSIC, Madrid}

Se trata de dar una breve visión del corral de animales domésticos, vinculado a las unidades familiares, en la cultura rural española. La enorme incidencia económica, especialmente de gallos y gallinas, dentro de unos planteamientos autoabastecedores, ha generado una rica reelaboración antropológica con expresiones, refranes, ritos y creencias relativas a estas aves.

This paper deals with a brief view of the domestic animals farmyard linked to family unites in the rural spanish culture. The enormous economic incidence, particularly of cocks and hens, within a selfprovisioning basis, has generated a rich anthropological reelaboration with expressions, proverbs, rites and beliefs to these fowls. 